\title{
Hermeneutik der frühchristlichen Wundererzählungen
}

\author{
Geschichtliche, literarische und rezeptionsorientierte Perspektiven \\ Hrsg. v. Bernd Kollmann u. Ruben Zimmermann
}

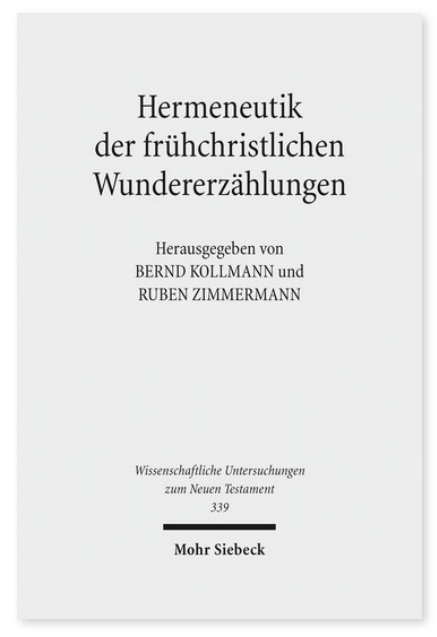

2014. XII, 716 Seiten. WUNT I 339

ISBN 978-3-16-152466-0 DOI 10.1628/978-3-16-152466-0 eBook PDF 194,00€ ISBN 978-3-16-152465-3 Leinen $194,00 €$
Der vorliegende Sammelband zur Hermeneutik der frühchristlichen Wundererzählungen bündelt den aktuellen Forschungsstand und führt die Diskussion weiter. Neben der Erörterung von Grundfragen werden die frühchristlichen Wundergeschichten vor dem Hintergrund ihres antiken Umfelds beleuchtet. Dabei kommen auch religionsgeschichtliche Aspekte (Wunder im Kaiserkult; Verhältnis der frühchristlichen Wundergeschichten zur hellenistischen Medizin; Beziehung Jesu zu anderen Wundertätern der Antike) in den Blick. Es schließen sich Erwägungen zur sprachlichen Gestalt, narratologischen Struktur und literarischen Form der Wundergeschichten an. Den Abschluss bildet eine Reihe von Beiträgen, die sich gezielt mit der Gegenwartsbedeutung der frühchristlichen Wundergeschichten beschäftigen. Neben tiefenpsychologischen, feministischen und kulturanthropologischen Zugängen kommt dabei auch die Bedeutung der Wundergeschichten für die Praxisfelder Schule und Diakonie zur Sprache.

\section{Inhaltsübersicht}

I. Grundfragen Bernd Kollmann: Rehabilitierung mythischen Denkens. Die Auslegung von Wundererzählungen in der neutestamentlichen Forschung - Craig S. Keener: Miracle Reports: Perspectives, Analogies, Explanations

II. Geschichtliche Perspektiven (einschließlich Traditions- und Religionsgeschichte) Axe/ Graupner: Wunder über Wunder. Israels Führung durch die Wüste Exodus 15,22-18,27 - Detlev Dormeyer: Wundergeschichten in der hellenistischen Medizin und Geschichtsschreibung. Eine religionsgeschichtliche Annäherung - Manfred Clauss: Wunder und Kaiserkult - Eric Eve: Jesus' Miracles in their Historical and Cultural Context - Graham H. Twelftree: Exorcism in Early Christianity - Reinhard von Bendemann: Elementar feurige Hitze - Zur Krankheitshermeneutik frühjüdischer, hellenistisch-römischer und frühchristlicher Fieberheilungen - Erkie Koskenniemi: Apollonius of Tyana, the Greek Miracle Workers in the Time of Jesus and the New Testament - Marco Frenschkowski: Antike kritische und skeptische Stimmen zum Wunderglauben als Dialogpartner des frühen Christentums

II. Sprachliche Perspektiven Gerd Theißen: Wunder Jesu und urchristliche Wundergeschichten. Historische, psychologische und theologische Aspekte - Ruben Zimmermann: Fantastische Tatsachenberichte . Zur Gattung 'Wundererzählung' - ein literaturwissenschaftlicher Versuch - Kristina Dronsch: In Wunder verstrickt. Eine medio-theologische Pointe der Wundergeschichten im Markusevangelium - Paul Borgman: Pattern and Purpose in John's Gospel: the Seven Miracle Stories Cornelis Bennema: Character Analysis and Miracle Stories in the Gospel of Mark - Michael Labahn: Wunder verändern die Welt. Überlegungen zum sinnkonstruierenden Charakter von Wundererzählungen am Beispiel der so genannten »Geschenkwunder - Istvan Czachesz: How to Read Miracle Stories with Cognitive Theory. On Harry Potter, Magic, and Miracle

III. Rezeptionsästhetische Perspektiven Eugen Drewermann: Tiefenpsychologische Hermeneutik von Wundererzählungen Stefan Alkier: Das Kreuz mit den Wundern oder Wunder ohne Kreuz? Semiotische, exegetische und theologische Argumente wider die formgeschichtliche Verkürzung der Wunderforschung - Christian Münch: Erzählung und Ereignis. Zur theologischen Deutung der Wundergeschichten - Wendy J. Cotter, SC): The Function of the Outrageous Petitioner in Pre-Markan Miracle Anecdotes - Susanne Luther: Die ethische Signifikanz der Wunder. Eine Relecture der Wundererzählungen der apokryphen Thomasakten unter ethischer Perspektive - Pieter Craffert: What Actually Happened? Miracle Stories in Anthropological Historical Perspective - Annike Reiß: Mit Kindern und Jugendlichen über Wunder theologisieren - Reinhold Zwick: Die Wunder Jesu im Film. Grenzfall der Ästhetik und (film-)theologische Herausforderung - Ulrike Metternich: Wunderdeutungen in der Feministischen Theologie und Bibelwissenschaft - Markus Schiefer Ferrari: Gestörte Lektüre der Wundererzählungen. Dis/abilitykritische Hermeneutik biblischer Heilungserzählungen am Beispiel von Mk 2,1-12

Bernd Kollmann 1989 Promotion, 1995 Habilitation in Göttingen; 1996-2000 Vertretungsprofessuren in Aachen und Siegen; seit 2000 Professor für Neues Testament an der Universität Siegen.

Ruben Zimmermann Born 1968; 1999 Dr. theol. from the University of Heidelberg; 2003 Habilitation from the LudwigMaximilians-University München; currently Professor of New Testament and Ethics at the Johannes Gutenberg-University in Mainz, Germany and research associate at the Department of Old and New Testament Studies of the University of the Free State, Bloemfontein, South Africa.

https://orcid.org/0000-0002-1620-4396

Jetzt bestellen:

https://mohrsiebeck.com/buch/hermeneutik-der-fruehchristlichen-wundererzaehlungen-9783161524660?no_cache=1 order@mohrsiebeck.com

Telefon: +49 (0)7071-923-17

Telefax: $+49(0) 7071-51104$ 